\title{
THE EFFECT OF ULTRASOUND EXPOSURE IN UTERO ON THE DEVELOPMENT OF THE FETAL MOUSE TESTIS: ADULT CONSEQUENCES
}

\author{
K. I. CARNes, ${ }^{\dagger}$ R. A. Hess ${ }^{\ddagger}$ and F. DunN ${ }^{\dagger}$ \\ ${ }^{\dagger}$ Bioacoustics Research Laboratory, Beckman Institute of Advanced Science and Technology and \\ ${ }^{\ddagger}$ Department of Veterinary Biosciences, College of Veterinary Medicine, \\ University of Illinois, Urbana, IL USA
}

(Received 17 February 1995; in final form 31 May 1995)

\begin{abstract}
The effects of exposure in utero to $1 \mathrm{MHz}$, continuous-wave ultrasound on adult growth and testicular development in the mouse was investigated. The spatial peak temporal average intensity $\left(I_{\text {SPTA }}\right)$ employed ranged from 1 to $10 \mathrm{~W} / \mathrm{cm}^{2}$, with exposure durations $(t)$ of $200 \mathrm{~s}$ to $20 \mathrm{~s}$. Exposures were made on days 9, 12 or 15 of gestation. Results showed an increase in postpartum deaths, an increase in the number of stillbirths, and a decrease in litter size when $I^{2} t \geq 1125 \mathrm{~W}^{2} \mathrm{~s} / \mathrm{cm}^{4}$, such that there was significant loss of pups. Birthweights of pups from nearly all dosage groups was significantly lower than that of the sham or cage control groups. Results also showed that males exposed to ultrasound in utero had decreased testis size and decreased duily sperm production ranging from $9 \%$ to $30 \%$. This study showed that ultrasound exposure in utero is capable of disrupting fetal development and having potential subsequent effects on fertility in the adult male.
\end{abstract}

Key Words: Adult testis, Exposure in utero, Ultrasound bioeffects, Daily sperm production, Sertoli cell, Postpartum death.

\section{INTRODUCTION}

Ultrasound has been used extensively worldwide for over three decades to monitor the health and development of the human fetus (Freiherr 1989). As a result of this usage, concern for the safety of the fetus prompted a number of animal studies designed to determine whether deleterious effects occur in a variety of biological systems following ultrasound exposure in utero. A number of these studies yielded positive results for fetal weight reduction and/or developmental abnormalities, some of which were subtle in nature (Carstensen and Gates 1985; O'Brien 1985; Siddiqi et al. 1988; Tarantal and Hendrickx, 1989a, 1989b).

A recent study, using the mouse as an animal model (Carnes et al. 1991b), demonstrated reduced fetal weight in litters exposed to ultrasound in utero, as well as increased incidence of stillbirths and resorptions. This study also showed effects on the development of the fetal testis which included a reduction in testis size and the number of Sertoli cells. Mitotic gonocytes were found to be present in the exposed

Address correspondence to: Prof. Floyd Dunn, Bioacoustics Research Laboratory, University of Illinois, 1406 W. Green Street, Urbana, IL 61801, USA. testes during a period when this cell division should have been quiescent. Such effects have the potential to induce long-term consequences on sperm production in the adult animal. The reduction in Sertoli cell number is of particular concern as the Sertoli cell is known to control testis size, as well as adult daily sperm production (Hess et al. 1993; Orth et al. 1988). Experimental destruction of Sertoli cells in the fetus has been shown to result in reduced sperm production in the adult (Orth et al. 1988). The present study was undertaken to determine if the effects of ultrasound exposure in utero were permanent and how they may be manifested in the adult male. Coincident with the effects on male reproduction, the effects of exposure to ultrasound in utero on growth and viability of the postpartum animal were also investigated.

\section{MATERIALS AND METHODS}

Animal care and mating

All animals were housed in the same animal care room. They were maintained on a 14:10-h light:dark schedule with food (Purina rat chow) and water dispensed ad libitum. Male mice were housed in close proximity to females to ensure regular 4 - to 5-day 
estrous cycles (Whittingham and Wood 1983). Ethical and humane standards governing the care and use of animals for experimental purposes were maintained at all times throughout the course of the study.

Female nulliparous ICR:HD (Harlan SpragueDawley, Indianapolis, IN, USA) mice, 70 to 100 days of age in proestrus or estrus, as determined by vaginal smears, were mated to fertile males in the afternoon. The following morning (day 0 ) the males were removed and females with seminal plugs or sperm-positive vaginal smears were set aside for exposure to ultrasound on day 9,12 or 15 postcoitus ( $\mathrm{pc}$ ).

Following the exposure, dams were placed in individual cages and allowed normal delivery on day 19 pc. On the morning of birth, the pups were counted and weighed individually. On day 21 postpartum (pp) the pups were weighed, weaned and separated according to sex. Siblings of the same sex were housed together in the same cage until killing on day $50 \mathrm{pp}$.

\section{Ultrasound exposure system and calibration}

Figure 1 illustrates the exposure system used, which included a Hewlett-Packard (Palo Alto, CA, USA) signal generator, an ENI (Rochester, NY, USA) RF power amplifier, and a 1-in.-diameter $(2.54 \mathrm{~cm})$ PZT-4, 1-MHz unfocused ultrasound transducer. The 1-MHz unfocused transducer acoustic field had a $95 \%$ power beam width of $1 \mathrm{~cm}$ and a $3-\mathrm{dB}$ beam width of $1.9 \mathrm{~cm}$. Primary calibration of the spatial peak, temporal average acoustic intensity output $\left(I_{\text {SPTA }}\right)$ was carried out by determining the force exerted on a small $\frac{1}{16}$-in. diameter $(0.16 \mathrm{~cm})$ steel sphere and was accurate to $\pm 3 \%$ (Dunn et al. 1977). The calibration was carried out at the same location in the sound field at which the specimen was positioned for the exposure procedure. The ultrasonic beam pattern was determined by the transient thermoelectric method (Fry and Dunn 1962).

\section{Experimental procedures}

The dams were anesthetized on the day of exposure with methoxyflurane (Metofane, Pitman-Moore) inhalation, shaved and depilated on the abdomen, back. and sides, and swabbed with a mild detergent solution to affect wetting of the skin. Depilation was necessary to remove hair stubble, which can trap air bubbles that would significantly distort the sound field. The specimen, mounted in a specially designed holder, was placed in the Plexiglas exposure tank filled with degassed mammalian Ringer's solution maintained at $37^{\circ} \mathrm{C}$, such that the abdomen faced the transducer and was perpendicular to the ultrasound beam axis (see Fig. 1 ). The muzzle of the animal protruded above the degassed water sound transmission medium and was fitted into the nose cone of the anesthesia circulator mounted on the holder, which maintained anesthesia throughout the exposure procedure.

A $2 \times 3$ exposure matrix (two exposure sites across the abdomen and three down ) over the abdominal area was employed to assure uniform exposure over the entire uterus. This was accomplished by maintaining the holder and animal stationary, while moving the transducer (with the sound off) to each of the six predetermined exposure positions. A digital positionindicating device was used to maintain the $1-\mathrm{cm}$ center-to-center distance between exposure positions such that the exposure overlap did not occur. The pattern of exposure was the same for all animals.

Groups of six dams, four exposed and two shams, were used for each of the ultrasound doses, i.e., for each pair of acoustic intensity $(I)$ and duration of exposure $(t)$ parameters, for each of the 3 days of gestation during which the exposures were carried out. Shamexposed animals were treated identically as the ultrasound exposed animals, with the exception that the transducer was not energized and so $I=0$. A group of eight cage control litters were also assessed to determine if any aspect of the preparation procedure could affect the experimental subjects. The cage control animals were randomly selected throughout the entire course of the study to continually monitor the animal colony.

Six ultrasound doses were used: $1 \mathrm{~W} / \mathrm{cm}^{2}$ for 200

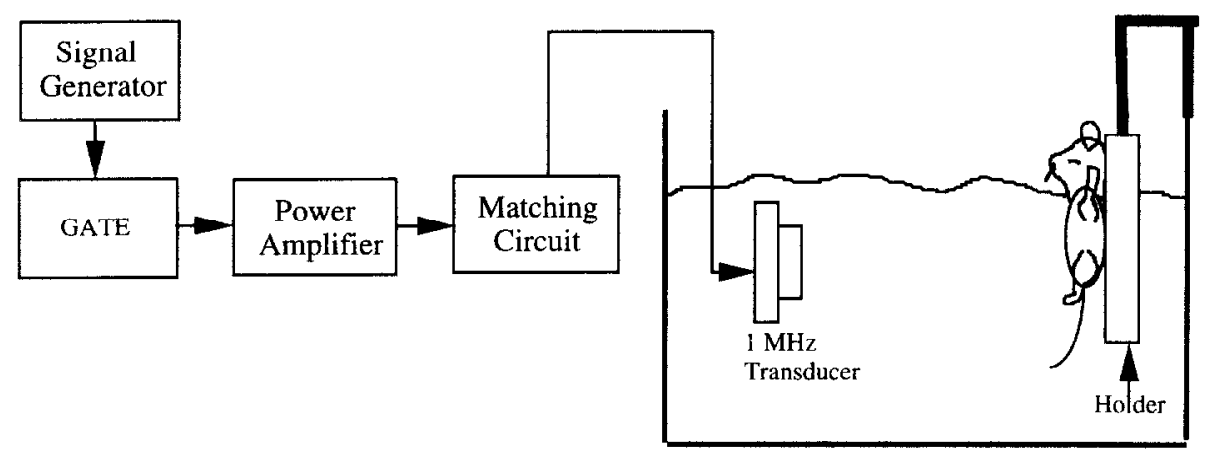

Fig. 1. Schematic representation of the exposure system. 


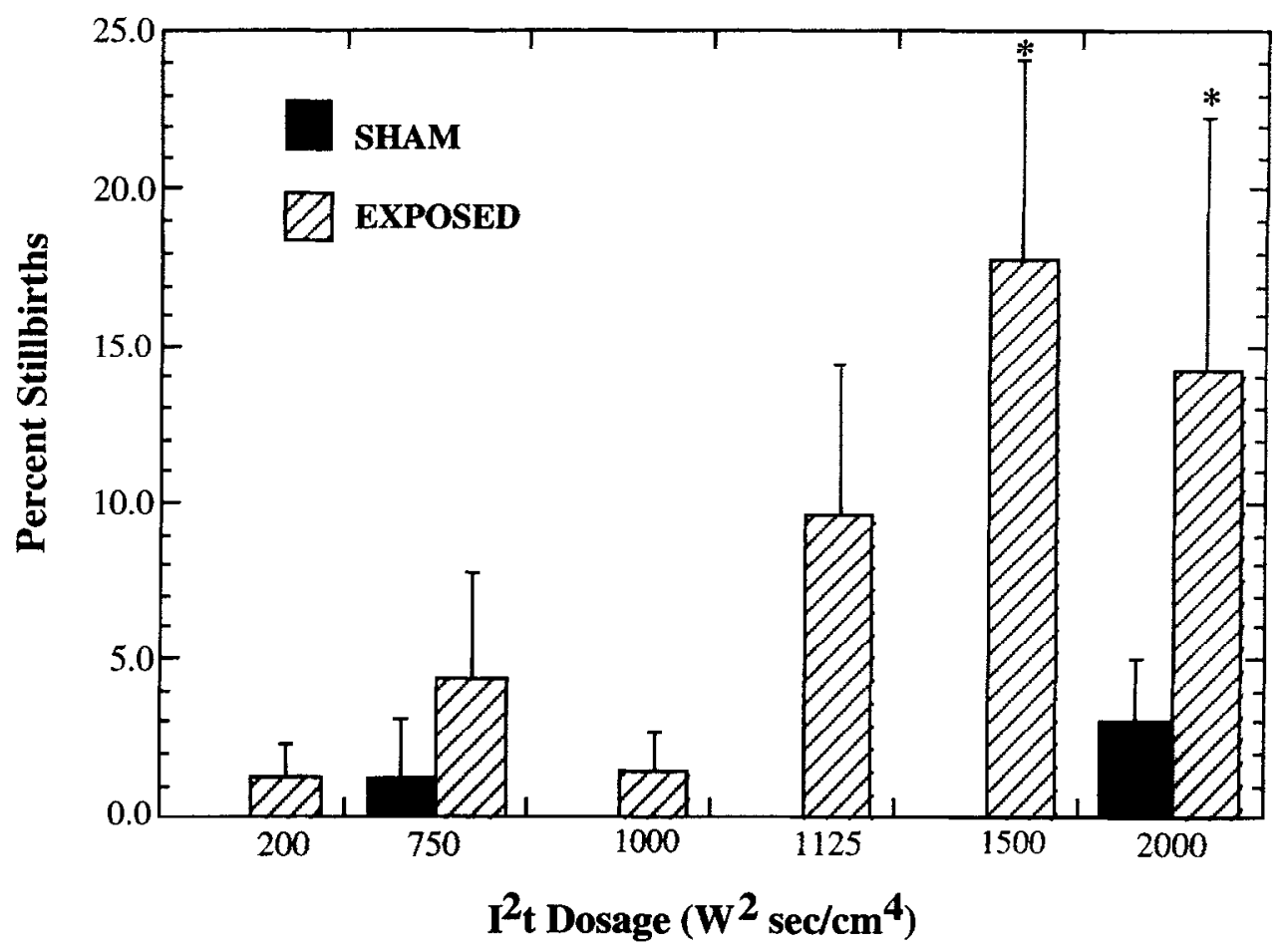

Fig. 2. Effect of ultrasound dosage on the number of stillbirths. Values are the mean percentage of stillbirths per treatment group. Asterisks indicate values that are significantly different $(p \leq 0.05)$ from the sham group. The cage control value was 0 . Error bars are the SEM.

$\mathrm{s}\left(I^{2} t=200 \mathrm{~W}^{2} \mathrm{~s} / \mathrm{cm}^{4}\right), 5 \mathrm{~W} / \mathrm{cm}^{2}$ for $30 \mathrm{~s}\left(I^{2} t=\right.$ $\left.750 \mathrm{~W}^{2} \mathrm{~s} / \mathrm{cm}^{4}\right), 5 \mathrm{~W} / \mathrm{cm}^{2}$ for $45 \mathrm{~s}\left(I^{2} t=1125 \mathrm{~W}^{2}\right.$ $\left.\mathrm{s} / \mathrm{cm}^{4}\right), 10 \mathrm{~W} / \mathrm{cm}^{2}$ for $10 \mathrm{~s}\left(I^{2} t=1000 \mathrm{~W}^{2} \mathrm{~s} / \mathrm{cm}^{4}\right)$, $15 \mathrm{~s}\left(I^{2} t=1500 \mathrm{~W}^{2} \mathrm{~s} / \mathrm{cm}^{4}\right)$, or $20 \mathrm{~s}\left(I^{2} t=2000 \mathrm{~W}^{2} \mathrm{~s} /\right.$ $\left.\mathrm{cm}^{4}\right)$. The $1 \mathrm{~W} / \mathrm{cm}^{2}$ intensity is in the range of clinical therapeutic ultrasound intensities. The remainder of the dosages were repeats of dosages used in the previous study (Carnes et al. 1991b), some of which are at the level experienced in the use of continuous-wave $(\mathrm{CW})$ Doppler ultrasound. Treatments were given on day 9 , 12 or $15 \mathrm{pc}$. These days of gestation were chosen for exposure because of the specific events occurring in male gonadal development at those times (Carnes et al. 1991b).

After ultrasonic exposure, the dams were dried, allowed to recover from the anesthetic, placed in individual cages and then returned to the animal quarters and allowed to give birth normally on day $19 \mathrm{pc}$.

The offspring exposed in utero were euthanized on day $50 \mathrm{pp}$. All females were euthanized by cervical dislocation, weighed, and a vaginal smear taken to determine the stage of estrous. Ovaries from three randomly selected females from each litter were placed in Bouin's fixative followed by $50 \%$ ethanol rinse and storage in $70 \%$ ethanol for future histological analysis.

The males were weighed and anesthetized with sodium pentobarbital. The right testis, which was removed, weighed and measured (length and width) was placed in mammalian Ringer's and frozen for subsequent determination of daily sperm production. The left testis from three randomly selected males from each litter was fixed by vascular perfusion (3\% gluteraldehyde in $0.05 \mathrm{~mol} / \mathrm{L}$ cacodylate buffer plus $2.5 \%$ polyvinylpyrrolidone). The perfused testis was removed, weighed, measured (length and width), and then placed in vials of the fixative for histological preparation. The remainder of the males from each litter were euthanized by cervical dislocation and weighed. The right testis was weighed, measured, placed in mammalian Ringer's and frozen for determination of daily sperm production. The left testis was weighed, measured, and fixed in Bouin's solution for histological evaluation.

\section{Determination of sperm production}

Daily sperm production (DSP) was determined by the procedure of Robb et al. (1978) with modifications. Briefly, the testis was thawed, the tunica albuginea removed and the testis reweighed. The testis was then homogenized for $2 \mathrm{~min}$ in $25 \mathrm{~mL}$ of physiological saline which contained $0.05 \%$ (vol/vol) Triton X-100. For counting, $0.1 \mathrm{~mL}$ of the homogenate was added to 0.4 $\mathrm{mL}$ normal saline containing 4\% Trypan blue. Tenmicroliter aliquots were placed on a hemocytometer and the surviving step 17 to 19 spermatids were counted using a microscope. These counts determined the total spermatids per sample, which were used to calculate 


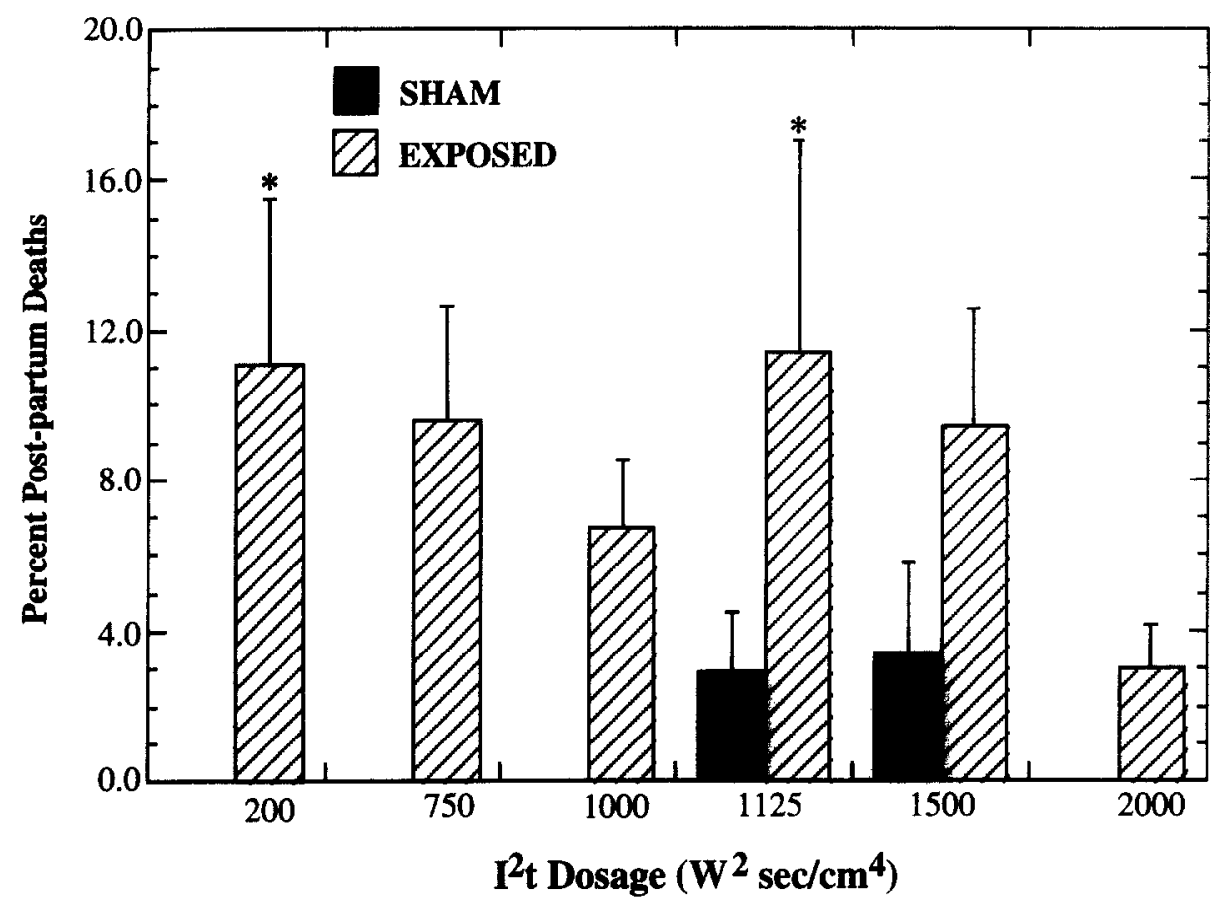

Fig. 3. Mean percentage of postpartum deaths for exposed and sham groups. Asterisks indicate values which are significantly different $(p \leq 0.05)$ from the shams. Error bars are the SEM. Cage control value was 0.

the total number of spermatids per testis. As round spermatids undergo elongation during sperm development, the nucleoprotein becomes highly condensed and cross- linked. Thus, the nucleus becomes resistant to homogenization while the nuclear material of other cells is destroyed (Amann 1982).

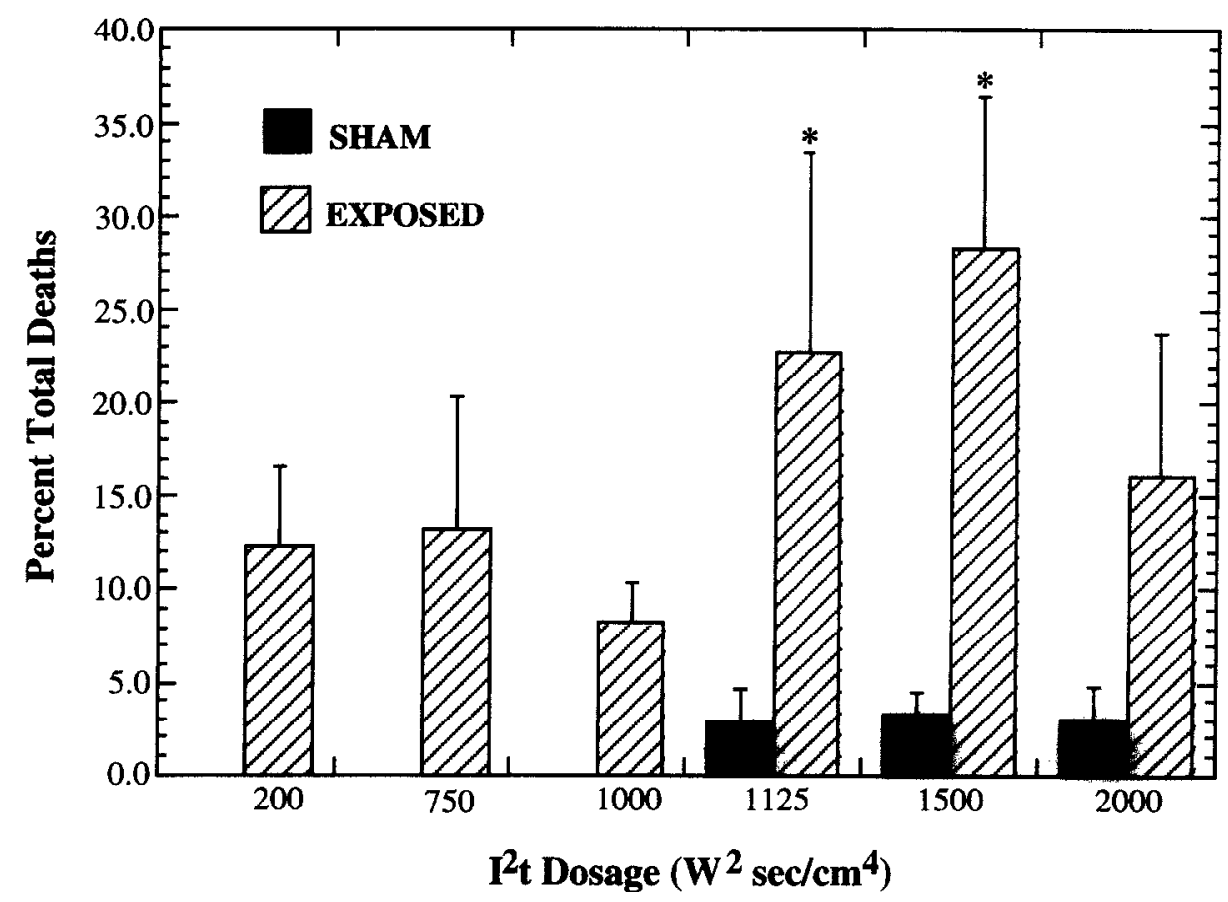

Fig. 4. Mean percentage of the total number of deaths (stillbirths and postpartum deaths) per treatment group, resulting from ultrasound exposure in utero. Asterisks indicate values which are significantly different $(p \leq 0.05)$ from the sham group. Error bars are the SEM. Cage control value was 0. 
Table 1. The effect of ultrasound exposure on litter size (number of live births) (mean \pm SD).

\begin{tabular}{crrrr}
\hline & & \multicolumn{3}{c}{ Day of exposure in utero } \\
\cline { 4 - 5 }$\left(\mathrm{W}^{2} \mathrm{dosage} / \mathrm{cm}^{4}\right)$ & Sham & Day 9 & Day 12 & Day 15 \\
\hline 200 & $12.0 \pm 0.0$ & $12.7 \pm 2.9$ & $11.7 \pm 2.3$ & $12.3 \pm 3.8$ \\
750 & $9.4 \pm 3.0$ & $8.7 \pm 2.1$ & $11.3 \pm 3.1$ & $13.3 \pm 1.5$ \\
1000 & $9.2 \pm 2.3$ & $11.7 \pm 2.5$ & $10.7 \pm 1.5$ & $12.0 \pm 1.0$ \\
1125 & $11.0 \pm 2.9$ & & $5.7 \pm 1.5^{\mathrm{a}}$ & $11.7 \pm 2.1$ \\
1500 & $10.8 \pm 3.1$ & $4.7 \pm 0.6^{\mathrm{a}}$ & $10.0 \pm 4.4$ & $8.0 \pm 5.6$ \\
2000 & $11.5 \pm 3.0$ & $9.0 \pm 1.4$ & $7.0 \pm 8.7^{\mathrm{a}}$ & $10.0 \pm 1.7$ \\
Cage control & $11.9 \pm 2.8$ & & & \\
\hline
\end{tabular}

"Significantly different $(p<0.05)$ from the sham values.

In the ICR mouse, developing spermatids spend approximately 4.8 days in steps 17 to 19 (Oakberg 1956) during spermatogenesis. DSP was determined by dividing the total number of spermatids by 4.8 .

\section{Testis cell counts}

To determine the testicular cells that may contribute to a decrease in DSP, cell counts were made of exposed testes for the $10-\mathrm{W} / \mathrm{cm}^{2}, 20$-s exposures which occurred on days 12 and 15 , as well as for the sham-exposure group. The number of round spermatids and Sertoli cell nucleoli in Stage VII round seminiferous tubule cross-sections were counted. For Stage XII, the number of Sertoli cell nucleoli, pachytene spermatocytes and degenerating germ cells were counted. Numbers were compared statistically by ANOVA.

\section{Statistical analysis}

Data were analyzed by one-way analysis of variance (ANOVA) using SYSTAT (Systat, Inc., Evanston, IL, USA). Percentage data were transformed by arcsine prior to analysis. Arcsine transformation is specified for proportions in order to stabilize variance prior to ANOVA (Snedecor and Cochran 1980). The Tukey-Kramer test of significant difference of the means was used to identify significant differences between groups (Stoline 1981). Differences were considered significant when $p<0.05$.

\section{RESULTS}

\section{Effect of ultrasound on litters}

Exposure to ultrasound in utero at all the doses employed produced effects on the viability of both the fetal and neonatal animals, as shown in Figs. 2, 3 and 4. These figures show, respectively, the mean percentage of stillbirths (Fig. 2), postpartum deaths (Fig. 3) and total deaths (Fig. 3 ) per litter between the exposed and sham-exposed groups. The cage control litters had no stillbirths or postpartum deaths. The incidence of stillbirths increased with increasing $I^{2} t$ dosage and was significantly different from the shams at the two highest dosages (see Fig. 2). Only one sham group had stillbirths.

The mean percentage per litter of postpartum deaths for each dosage is presented in Fig. 3. While all exposure groups had a greater incidence of postpartum deaths than the sham groups, two treatment groups had a significantly greater number, the $I^{2} t=200 \mathrm{~W}^{2} \mathrm{~s} /$ $\mathrm{cm}^{4}$ group and the $I^{2} t=1125 \mathrm{~W}^{2} \mathrm{~s} / \mathrm{cm}^{4}$ group. Only two of the sham groups had any postpartum deaths.

The mean percentage total loss of animals (number of stillbirths and postpartum deaths combined) per litter is presented in Fig. 4. The incidence of loss was nearly equal for the lower three dosages and did not show a significant difference from that of the sham litters. The incidence of loss dramatically increased and became significantly different when $I^{2} t$ equaled $1125 \mathrm{~W}^{2} \mathrm{~s} / \mathrm{cm}^{4}$ and $1500 \mathrm{~W}^{2} \mathrm{~s} / \mathrm{cm}^{4}$. Following exposure to the highest dosage, the mean total loss was again higher than, but not significantly different from, the sham litters.

Not reflected in Figs. 2 to 4 is the influence of day of exposure on the number of deaths. The animals exposed on day 9 had a greater incidence of both stillbirths and postpartum deaths, $21.6 \%$ total loss, versus the animals exposed on day $12(11.9 \%)$ and day 15 ( $10.3 \%$ loss). The cage control group had a $0 \%$ total loss. The sham group had total losses of $0 \%, 1.85 \%$ and $1.5 \%$, from exposure days 9,12 and 15 , respectively. The total loss for all animals in the study was $0 \%$ for the cage control group ( $n=95), 1.1 \%$ for the sham group $(n=361)$ and $13.9 \%$ for the exposed group $(n=531)$.

Litter size (the total number of live births) was significantly reduced from that of the sham and cage control litters for the three dosages where $I^{2} t \geq 1125$ $\mathrm{W}^{2} \mathrm{~s} / \mathrm{cm}^{4}$ (see Table 1). Of the groups that were significantly smaller, only one, the D9, $I^{2} t=1500$ $\mathrm{W}^{2} \mathrm{~s} / \mathrm{cm}^{4}$, was decreased due to a large number of stillbirths. A reduction in litter size without the presence of stillborn pups can be construed as indirect 
Table 2. The effect of ultrasound exposure on birth weight ( $g$ ) (mean $\pm S D$ ).

\begin{tabular}{|c|c|c|c|c|}
\hline \multirow{2}{*}{$\begin{array}{l}\text { It dosagc } \\
\left(\mathrm{W}^{2} \mathrm{~s} / \mathrm{cm}^{+}\right)\end{array}$} & \multirow[b]{2}{*}{ Sham } & \multicolumn{3}{|c|}{ Day of exposure in there } \\
\hline & & Day 9 & Day 12 & Day 15 \\
\hline 200 & $1.50 \pm 0.12$ & $1.38 \pm 0.18^{\mathrm{a}}$ & $1.41 \pm 0.15$ & $1.41=0.09$ \\
\hline 750 & $1.51 \pm 0.14$ & $1.41 \pm 0.15^{a}$ & $1.46 \pm 0.10$ & $1.50 \pm 0.09$ \\
\hline 1000 & $1.58 \pm 0.14$ & $1.49 \pm 0.11^{\mathrm{a}}$ & $1.40 \pm 0.15^{\prime \prime}$ & $1.34 \pm 0.14$ \\
\hline 1125 & $1.56 \pm 0.07$ & & $1.26 \pm 0.09^{\prime \prime}$ & $1.37 \pm 0.09$ \\
\hline 1500 & $1.51 \pm 0.22$ & $1.36 \pm 0.07^{4}$ & $1.50 \pm 0.11$ & $1.42 \pm 0.13$ \\
\hline 2000 & $1.49 \pm 0.13$ & $1.61 \pm 0.08^{\mathrm{a}}$ & $1.48 \pm 0.03$ & $1.59 \pm 0.63$ \\
\hline Cage control & $1.54 \pm 0.12$ & & & \\
\hline
\end{tabular}

Significantly different $(p<0.05)$ from the sham groups

evidence of the occurrence of resorptions. A significant increase in the number of resorptions following ultrasound exposure in utero has been documented previously (Carnes et al. 1991b). Additionally, all the dams used in this study were nulliparous so that parity would not affect litter size.

Ultrasound exposure also caused a significantly lowered birthweight (Table 2) for 10 of the 17 dosage/ gestational day combinations. However, a pronounced dose effect was not apparent. Animals exposed on day 9 to the highest dosage were significantly heavier than the sham animals.

The reduction in weight at birth in the animals exposed to ultrasound on day $9 \mathrm{pc}$ appeared to be transitory as they caught up in weight with the sham and cage control groups by weaning (Table 3 ) and showed no difference at day 50 (see Tables 4 and 5 ). It should be noted that the $I^{2} t=750 \mathrm{~W}^{2} \mathrm{~s} / \mathrm{cm}^{4}$ dosage males had significantly lower weights at time of killing than did the shams for that group, but were not significantly lower than the cage controls. Males that received the $I^{2} t=2000 \mathrm{~W}^{2} \mathrm{~s} / \mathrm{cm}^{4}$ dosage were higher in weight than the shams and cage controls from birth through killing. The day 9 exposed females exhibited no significant weight changes.

Animals exposed to ultrasound on day 12 exhibited confusing results. While only three of the six groups showed lowered birthweights, ultrasound-ex- posed animals from all six exposure dosages had significant differences in weaning weights from the respective shams. One half had lower weaning weights and one half had higher weaning weights. Of those dosage groups that had significantly higher weaning weights, the $I^{2} t=200 \mathrm{~W}^{2} \mathrm{~s} / \mathrm{cm}^{4}$ group was not significantly different from the cage controls. Therefore, the increase in weaning weights may be due in part to a smaller litter size (see Table 1), as the two dosages that had significantly increased weaning weights also showed significantly decreased litter size. The increased weight of these two groups persisted to day 50 in the males (Table 4). Animals receiving $I^{2} t=$ $1000 \mathrm{~W}^{2} \mathrm{~s} / \mathrm{cm}^{4}$ dosage never caught up in weight to the shams and cage controls and the males continued to be significantly lower in weight on day 50 . The females of this dosage group were significantly lower in weight at time of killing than the shams, but not significantly lower than the cage controls (Table 5).

The same $I^{2} t$ dosages that caused reduced birthweight following day 12 exposure also resulted in reduced birthweight following day 15 exposure (Table 5). In this case, only one dosage $\left(I^{2} t=1000 \mathrm{~W}^{2}\right.$ $\mathrm{s} / \mathrm{cm}^{4}$ ) showed a significant difference from both the shams and cage controls at weaning and two other groups were significantly lower than the cage controls but not the shams. Three dosages given on day 15 showed significantly lower body weights than the sham

Table 3. The effect of ultrasound on body weight $(\mathrm{g})$ at weaning (mean $\pm \mathrm{SEM}$ ).

\begin{tabular}{ccccc}
\hline & & \multicolumn{3}{c}{ Day of exposure in utero } \\
\cline { 4 - 5 }$\left(\mathrm{W}^{2} \mathrm{~s} / \mathrm{cm}^{4}\right)$ & Sham & Day 9 & Day 12 & Day 15 \\
\hline 200 & $10.0 \pm 2.5$ & $9.6 \pm 3.4$ & $11.7 \pm 1.5^{\mathrm{a}}$ & $9.3 \pm 3.1$ \\
750 & $12.3 \pm 2.1$ & $11.3 \pm 1.6$ & $10.7 \pm 1.2^{\mathrm{a}}$ & $11.6 \pm 1.3$ \\
1000 & $12.7 \pm 2.4$ & $12.0 \pm 1.2$ & $10.1 \pm 2.2^{\mathrm{a}}$ & $10.6 \pm 1.5^{\mathrm{a}}$ \\
1125 & $11.9 \pm 0.1$ & $11.6 \pm 0.7$ & $14.6 \pm 1.6^{\mathrm{a}}$ & $10.7 \pm 1.1$ \\
1500 & $12.8 \pm 3.3$ & $14.8 \pm 3.3^{\mathrm{a}}$ & $10.6 \pm 2.2^{\mathrm{a}}$ & $1.4 \pm 1.4$ \\
2000 & $10.1 \pm 2.7$ & & $13.3 \pm 3.1^{\mathrm{a}}$ & $10.3 \pm 2.8$ \\
Cage control & $11.7+1.5$ & & & \\
\hline
\end{tabular}

a Significantly different $(p<0.05)$ from the sham groups. 
Table 4. The effect of ultrasound exposure on body weight $(\mathrm{g})$ of males at day 50 (mean \pm SD).

\begin{tabular}{ccccc}
\hline & & \multicolumn{3}{c}{ Day of exposure in utero } \\
\cline { 4 - 5 }$I^{2} t$ dosage \\
$\left(\mathrm{W}^{2} \mathrm{~s} / \mathrm{cm}^{4}\right)$
\end{tabular}

a Significantly different $(p<0.05)$ from the sham groups.

males on day 50 . However, as was the case of the day 9 exposures, males exposed to $I^{2} t=750 \mathrm{~W}^{2} \mathrm{~s} / \mathrm{cm}^{4}$ and $1000 \mathrm{~W}^{2} \mathrm{~s} / \mathrm{cm}^{4}$ were different from the sham group but not the cage control group and the $I^{2} t=$ $1125 \mathrm{~W}^{2} \mathrm{~s} / \mathrm{cm}^{4}$ dosage group was different from the cage control group but not different from the sham group.

\section{Testis effects}

Adult testicular weights were significantly reduced in 6 of the 17 exposed groups compared to the sham and/or cage control groups (Fig. 5). Mean testis weight in the $I^{2} t=2000 \mathrm{~W}^{2} \mathrm{~s} / \mathrm{cm}^{4}$, day 15 group was significantly higher than the shams, but not higher than the cage controls.

The data regarding testicular volume is presented in Fig. 6. Seven exposure groups, indicated by the asterisks, had mean testis volumes which were significantly lower than the sham and/or cage control groups. None of the groups had testis volumes that were unusually high, suggesting that edema or swelling is not a factor following ultrasound exposure in utero. All of the groups exposed on day $9 \mathrm{pc}$ had significantly reduced testicular volumes.

Daily sperm production (DSP) data is presented in Fig. 7. DSP was significantly decreased from that of the shams and/or cage controls for several exposed groups and was significantly elevated compared to the sham, but not the cage control for one group $\left(I^{2} t=\right.$
$1125 \mathrm{~W}^{2} \mathrm{~s} / \mathrm{cm}^{4}$, day 12). The $I^{2} t=2000 \mathrm{~W}^{2} \mathrm{~s} / \mathrm{cm}^{4}$ dosage significantly reduced DSP for all 3 exposure days, while testis weight was not affected and volume was only affected on day 9 .

There was a significant reduction $(p \leq 0.05)$ in the numbers of Sertoli cell nucleoli and the ratio of pachytene spermatocytes to Sertoli cell nucleoli/tubule cross-section in the animals exposed on day 15 of gestation as compared to the shams. This is shown in Table 6 for a group having a significant difference in daily sperm production. There was also an increase in the number of degenerating germ cells. No differences were found in any of the cell counts of animals exposed on day 12 of gestation.

\section{DISCUSSION}

It is evident from these results that in utero exposure of fetal mice to ultrasound at the dosages used in this study had adverse effects on fetal and neonatal mortality, as well as lasting effects on growth and reproductive capacity (DSP) of the male offspring. These effects are seen to be related to the $I^{2} t$ ultrasound parameter, which suggests that two mechanisms of action are responsible, one of which is heat and the other not identified. Precise fetal temperature increase measurements (Carnes et al. 1991a) and the lack of correlation with the $I^{2} t$ ultrasound parameter are strong evidence that heat alone is not the cause of the effects

Table 5. The effect of ultrasound exposure of body weight (g) of females at day 50 (mean \pm SD).

\begin{tabular}{ccccc}
\hline $\begin{array}{c}I^{2} t \text { dosage } \\
\left(\mathbf{W}^{2} \mathrm{~s} / \mathrm{cm}^{4}\right)\end{array}$ & Sham & Day 9 & $\begin{array}{c}\text { Day of exposure in utero } \\
\text { Day } 12\end{array}$ \\
\hline 200 & $25.8 \pm 2.0$ & $24.3 \pm 2.0$ & $25.7 \pm 2.3$ & Day 15 \\
750 & $26.0 \pm 2.5$ & $26.5 \pm 1.6$ & $26.2 \pm 2.0$ & $26.1 \pm 2.3$ \\
1000 & $27.3 \pm 3.1$ & $25.7 \pm 2.1$ & $23.3 \pm 1.5^{\mathrm{a}}$ & $25.8 \pm 1.7$ \\
1125 & $24.9 \pm 3.1$ & & $25.3 \pm 1.5$ & $23.0 \pm 2.4$ \\
1500 & $25.4 \pm 2.7$ & $25.2 \pm 2.3$ & $26.5 \pm 2.0$ & $23.3 \pm 3.4$ \\
2000 & $26.6 \pm 2.3$ & $27.1 \pm 1.5$ & $28.5 \pm 1.6$ & $25.5 \pm 1.8$ \\
Cage Control & $25.7 \pm 2.5$ & & & \\
\hline
\end{tabular}

\footnotetext{
a Significantly different $(p<0.05)$ from the sham groups.
} 


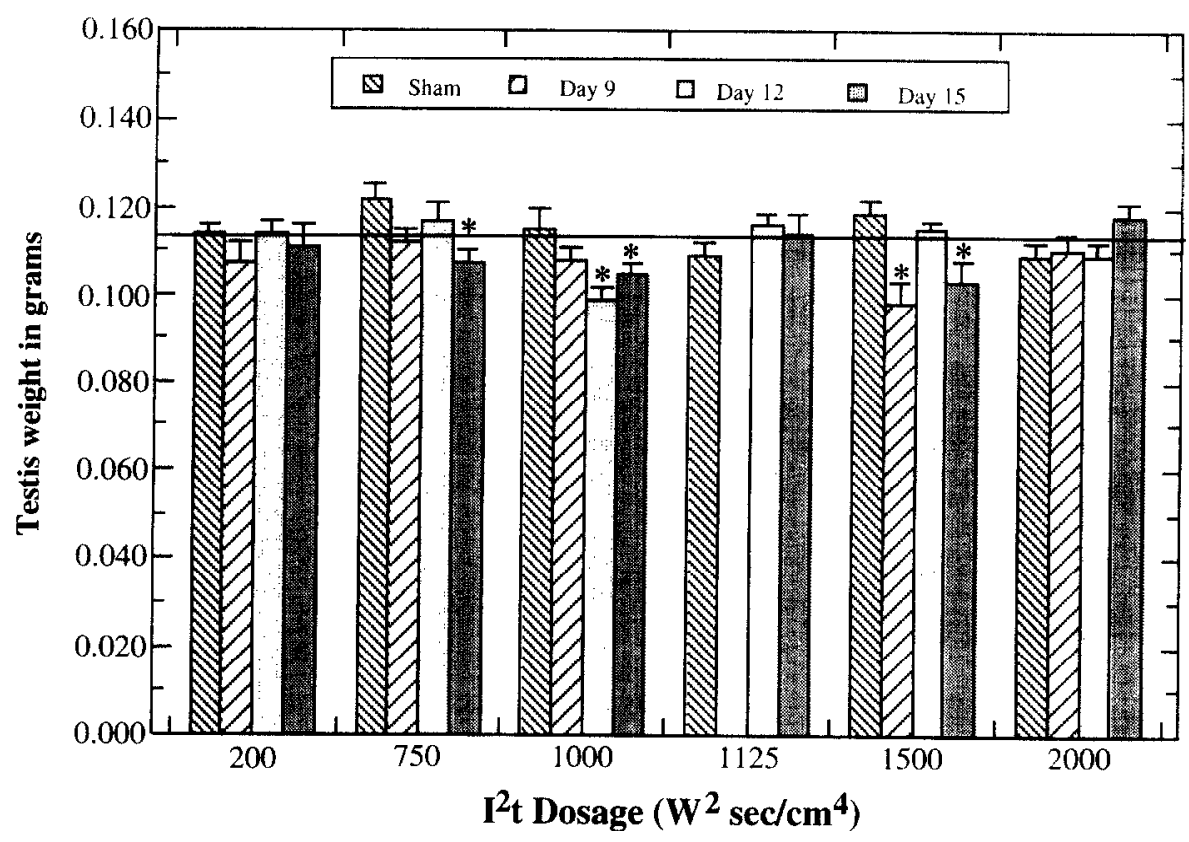

Fig. 5. Effect of ultrasound exposure in utero on adult testis weight. Asterisks indicate values that are significantly different $(p \leq 0.05)$ from the sham group. Error bars are the SEM. The solid line across the top represents the cage control value $(0.116 \pm 0.003 \mathrm{~g})$.

seen in this study. However, heat is a contributing factor, particularly when the $I^{2} t$ dosage is at or above $1125 \mathrm{~W}^{2} \mathrm{~s} / \mathrm{cm}^{4}$.

A two-mechanism theory is especially apparent when considering the data regarding mortality (Figs. 2,3 and 4 ). It was clearly seen that as the dosage increased, so did the incidence of stillbirths and probably resorptions as the litter size was significantly

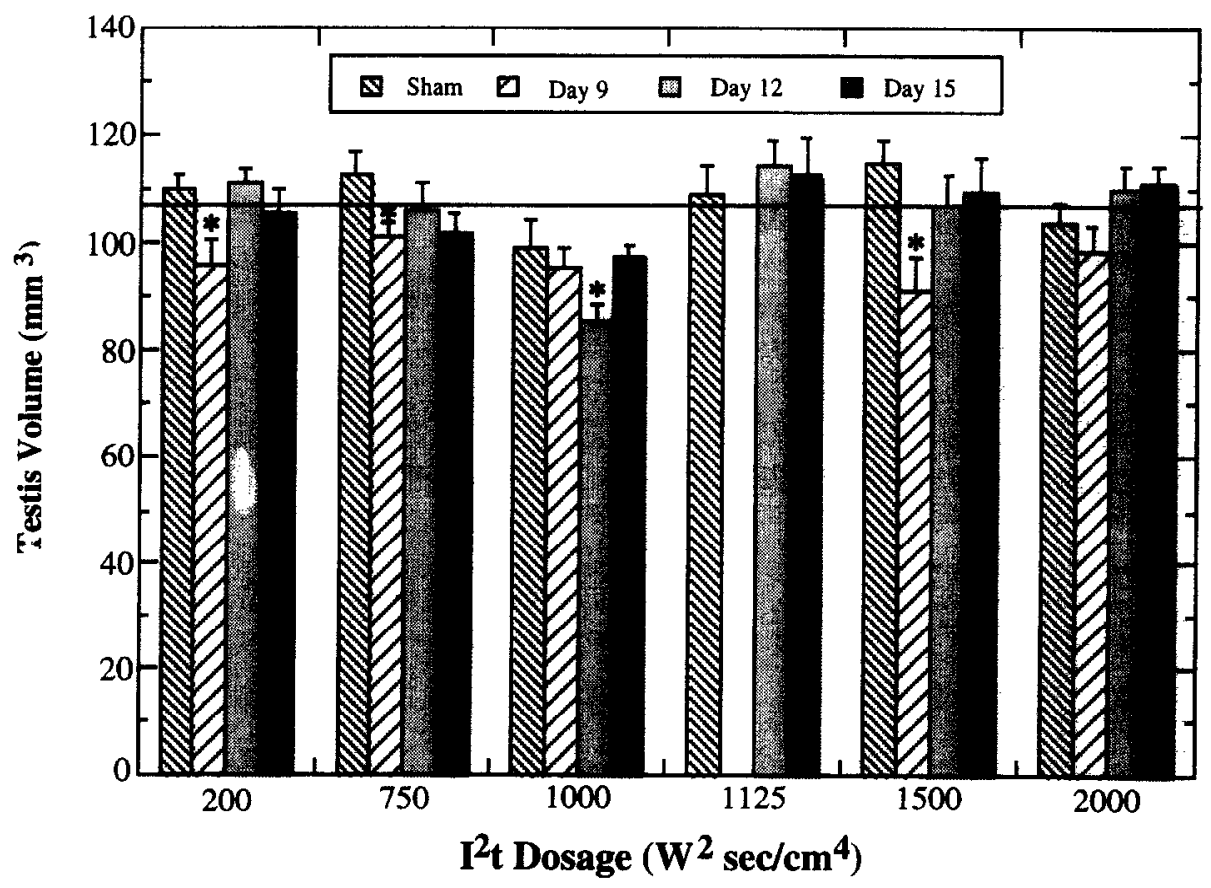

Fig. 6. Effect of ultrasound exposure in utero on adult testis volume. Asterisks indicate values that are significantly different $(p \leq 0.05)$ from the sham groups. Error bars are the SEM. The straight line represents the cage control value $\left(113.5 \pm 2.23 \mathrm{~mm}^{3}\right)$. 


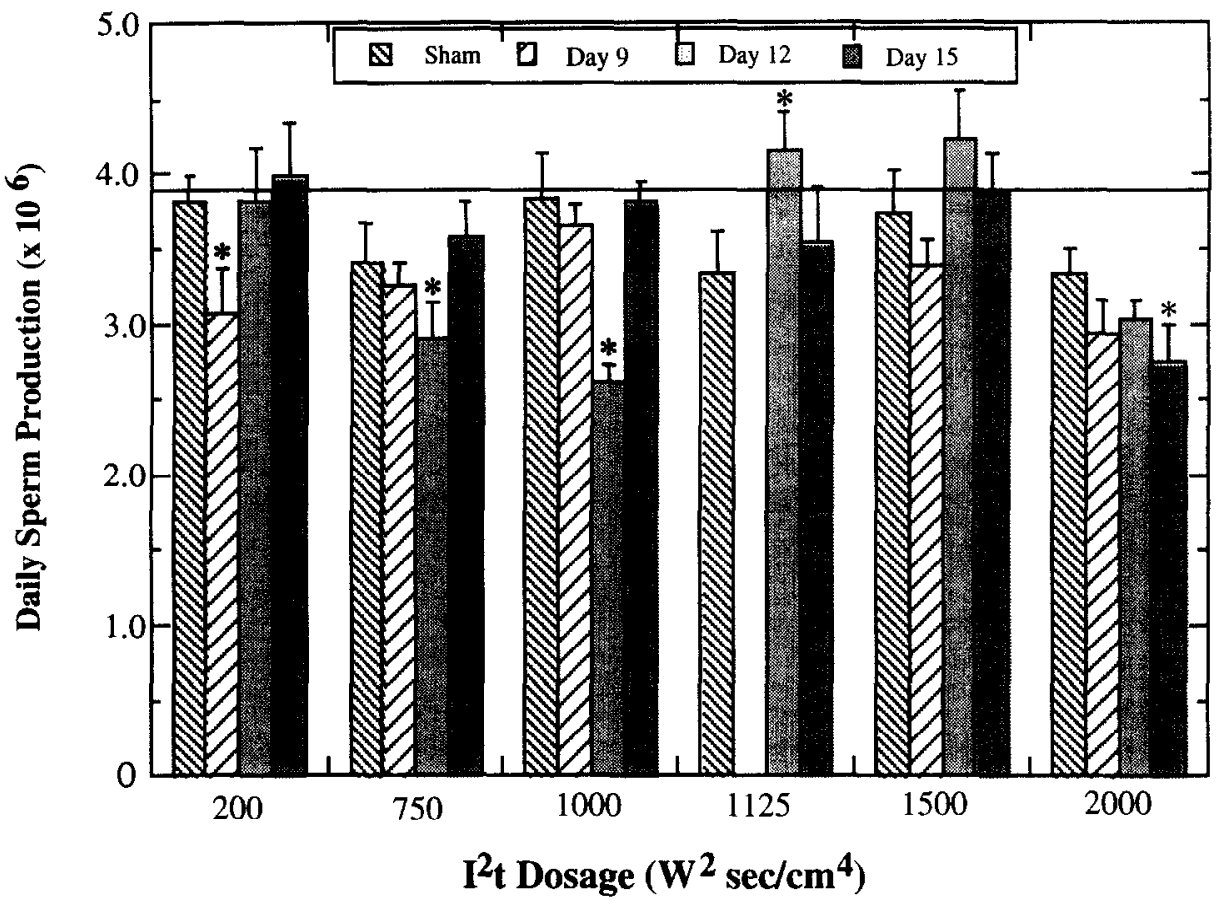

Fig. 7. The effect of ultrasound exposure in utero on daily sperm production of the adult. Asterisks indicate values that are significantly different $(p \leq 0.05)$ from the sham groups. The error bars are the SEM. The line represents the value of the cage control group $\left(3.88 \times 10^{6} \pm 0.18 \times 10^{6}\right)$.

smaller (Table 1). However, the incidence of postpartum deaths decreased with increasing ultrasound dosage. This suggests that, at the lower dosages, an "unidentified" mechanism is involved such that the fetus can survive in utero but cannot survive following birth, as the majority of postpartum deaths occurred within the first $24 \mathrm{~h}$ of life. At the higher dosages, heat becomes a factor and the fetuses die in utero and are either resorbed, if death occurs early in gestation, or are stillborn if death is late in gestation. The reason for the lower rate of mortality in the highest dosage group, $I^{2} t=2000 \mathrm{~W}^{2} \mathrm{~s} / \mathrm{cm}^{4}$, is not known.

The conflicting weaning weight data (Table 3 ) can be explained by the smaller litter size of the day 12 exposed animals. It has previously been established that weights of the young are dependent on the number of pups being reared (Brumby 1960). These litters were smaller in number at birth and also had large numbers of postpartum deaths, most of which occurred in the first week of life.

Fetal weight reduction is a common effect following in utero exposure to a variety of agents or insults, and results from various mechanisms. Cocaine (Scanlon 1991), nicotine (Zahalka et al. 1992) and carbon monoxide (Maines 1993) exert their effects by inhibiting oxygen uptake. The methylxanthines, caffeine, theobromine and theophylline, inhibit phosphodiesterase, act as an adenosine receptor antagonist and affect translocation of calcium (Rall et al. 1995). Maternal stress causes an increase in fetal ACTH and corticosterone and a decrease in fetal corticotrophin-releasing factor (CRF) and $\beta$-endorphins (Ohkawa et al. 1991). Lead (Ramin et al. 1993) and nitrites (Roth and Smith 1988 ) both affect iron metabolism, which also results in fetal growth retardation. 2,3,7,8-Tetrachlorodibenzo- $p$-dioxin (TCDD) is also known to cause reduced birthweight at some dosage levels but this was not a permanent effect (Mably et al. 1992). The mechanism of action of alcohol, with respect to fetal weight reduction, is unclear. Exposure to alcohol in utero is known to prevent the prenatal testosterone surge necessary for normal male reproductive development and again results in feminizing behavior as well as morphological and physiological effects (McGivern et al. 1988) not secn following ultrasound exposure.

With regard to male reproductive development and subsequent adult effects, estrogenic compounds such as diethylstilbestrol, ethinylestradiol and PCBs are thought to act on the pituitary by disruption of negative feedback, thereby changing the interplay of hormones necessary for normal male reproductive development (Sharpe and Skakkebaek 1993). These changes result in effects such as feminization of behavior, lack of testis decent and gonadal dysgenesis. As the latter two effects were not seen following in utero ultrasound exposure, it is unlikely that ultrasound causes an imbalance of pituitary hormones. Changes in reproductive behavior of the males following in utero 
Table 6. Effects of ultrasound exposure in utero on the adult testis.

\begin{tabular}{lcccc}
\hline Treatment & Pachytene spermatocytes & Sertoli cell nucleoli & Ratio & Degenerating germ cells \\
\hline Sham & $53.9 \pm 3.1$ & $9.3 \pm 0.71$ & $6.02 \pm 0.61$ & $0.267 \pm 0.278$ \\
Exposed & $54.7 \pm 2.8$ & $7.7 \pm 0.65^{\circ}$ & $7.92 \pm 0.56^{\circ}$ & $0.778 \pm 0.254^{\circ}$ \\
\hline
\end{tabular}

Ultrasound dosage of $10 \mathrm{~W} / \mathrm{cm}^{2}$ for $20 \mathrm{~s}$ on day $15 \mathrm{pc}\left(I^{2} t=2000 \mathrm{~W}^{2} \mathrm{~s} / \mathrm{cm}^{4}\right)$

"Mean (counts/tubule cross-section) \pm SEM.

'Significantly different $(p<0.05)$ from the sham group.

ultrasound exposure were not assessed, however. TCDD, another estrogenic compound, also causes demasculinization and feminized LH responses, but in addition results in similar effects as seen following in utero ultrasound exposure, namely reduced testis weight and lowered daily sperm production. It is unlikely that stress of the animals during exposure can explain the ultrasound effects seen in this study. Stress in utero results in endocrine changes which cause male feminization behavior similar to that produced by the estrogenic compounds (Pollard and Dyer 1985), though the effect on DSP was not reported.

There are, however, a number of similarities between the effects of caffeine and those of ultrasound both on general growth and male reproductive development. Dunlop and Court (1981) showed significant reduction in both birth weight and neonatal survival following caffeine exposure in utero. Pollard et al. (1990) showed growth effects following caffeine exposure in utero which persisted in the males of some dosage groups similar to that seen in the present study and, as with ultrasound, the females caught up with their sham counterparts. Caffeine has also been shown to delay fetal testicular development (McGivern et al. 1988 ) and involved the Sertoli cell in a manner similar to that seen following ultrasound exposure in utero (Carnes et al. 1991b). Pollard et al. (1987) also found a decrease in $3 \beta$-hydroxysteroid dehydrogenase concentrations at all dosages and a decrease in testosterone at the highest dosage which persisted into adulthood. They did not, however, measure DSP or other parameters of testicular function.

Results of the present study confirm that the fetal effects on testicular development previously seen following exposure to $1 \mathrm{MHz}$ ultrasound in utero (Carnes et al. 1991b) are permanent and detrimental to adult male reproductive capacity. The reduction in testis size and the number of Sertoli cell nucleoli per tubule crosssection leads to the conclusion that the establishment of the Sertoli cell population appears to be involved in the overall effect of ultrasound on testicular development. DSP in ultrasound exposed males was reduced from $9 \%$ to $33 \%$ lower than that of the cage controls or sham-exposed animals. Although this reduction is significant, it is probably not sufficient to reduce fertil- ity in the rodent, which produces numbers of sperm far in excess of that necessary for normal fertility (Working 1988). The situation is quite different for human males, as they tend to produce sperm near the threshold needed for normal fertility (Working 1988). Decreases in DSP, such as those seen in this study, would render human males either subfertile or infertile. Thus, ultrasound should be viewed as an agent capable of disrupting fetal development and having potential subsequent effects on fertility in the adult male.

Acknowledgements - The authors thank Robert Cicone for his technical assistance. The authors acknowledge gratefully support of this work by grants from the National Institutes of Health.

\section{REFERENCES}

Amann, R. P. Use of animal models for detecting specific alterations in reproduction. Fund. Appl. Toxicol. 2:13-20; 1982.

Brumby, P. J. The influence of the maternal environment on growth in mice. Heredity $14: 1-18 ; 1960$.

Carnes, K. I.; Drewniak, J. L.; Dunn, F. in utero measurement of ultrasonically induced fetal mouse temperature increases. Ultrasound Med. Biol. 17:373-382; 1991a.

Carnes, K. I.; Hess, R. A.; Dunn, F. Effects of in utero ultrasound on the development of the fetal mouse testis. Biol. Reprod. 45:432-439; $1991 \mathrm{~b}$

Carstensen, E. L.; Gates, A. H. Ultrasound and the fetus. In: Nyborg, W. L.; Ziskin, M. C., eds. Biological effects of ultrasound. Clinics in diagnostic ultrasound (vol. 16). Ncw York: Churchill Livingstone; $1985: 85-95$.

Dunlop, M.; Court, J. M. Effects of maternal caffeine ingestion on neonatal growth in rats. Biol. Neonate 39:178-184; 1981 .

Dunn, F.; Averbuch. A. J.; O'Brien, W. D., Jr. A primary method for the determination of ultrasonic intensity with the elastic sphere radiometer. Acustica 18:58-611; 1977.

Freiherr, G. Diagnostic ultrasound: Where is it headed? Diagn. Imag. $11: 94-103 ; 1989$

Fry, W. J.; Dunn, F. Ultrasound: analysis and experimental methods in biological research. In: Nastuk, W. L., ed. Physical techniques in biological research (vol. 4). New York: Academic Press 1962:261-394.

Hess, R. A.; Cooke, P. S.; Bunick, D.; Kirby, J. D. Adult testicular enlargement induced by neonatal hypothyroidism is accompanied by increased Sertoli and germ cell number. Endocrinology 132:2607-2613; 1993

Mably, T. A.; Moore, R. W.; Peterson, R. E. In utero and lactational exposure of male rats to 2,3,7,8-tetrachlorodibenzo- $p$-dioxin 1 . Effects on androgenic status. Tox. Appl. Pharm. 114:97-101; 1992.

Maines, M. D. Carbon monoxide: an emerging regulator of cGMP in the brain. Molec. Cell. Neurosci. 4:389-397; 1993.

McGivern, R. F.; Raum, W. J.; Slido, E.; Redie, E. Lack of prenatal testosterone surge in fetal rats exposed alcohol: alterations in testicular morphology and physiology. Alc. Clin. Exp. Res. 12:243-247; 1988 . 
O'Brien, W. D., Jr. Biological effects in laboratory animals. In: Nyborg, W. L.; Ziskin, M. C., eds. Biological effects of ultrasound. Clinics in diagnostic ultrasound (vol. 16). New York: Churchill Livingstone; 1985:77-84.

Oakberg, E. F. Duration of spermatogenesis in the mouse and timing of stages of the cycle of seminiferous epithelium. Am. J. Anat. 99:507-516; 1956.

Ohkawa, T.; Rohde, W.; Takeshita, S.; Dorner, G.; Arai, K.; Okinaga, S. Effect of an acute maternal stress of the fetal hypothalamo-pituitary-adrenal system in late gestational life of the rat. Exp. Clin. Endocrinol. 98:123-129; 1991.

Orth, J. M.; Gunsalus, G. L.; Lamperti, A. A. Evidence from Sertoli cell-depleted rats indicates that spermatid number in adults depends on numbers of Sertoli cells produced during perinatal development. Endocrinology $122: 787-794 ; 1988$.

Pollard, I.; Dyer, S. L. Effect of stress administered during pregnancy on the development of fetal testes and their subsequent function in the adult rat. J. Endocrinol. 107:241-245; 1985.

Pollard, I.; Jabbour, H.; Mehrabani, P. A. Effects of caffeine administered during pregnancy on fetal development and subsequent function in the adult rat: prolonged effects on a second generation. J. Tox. Environ. Health 22:1-15; 1987.

Pollard, I.; Williamson, S.; Magre, S. Influence of caffeinc administered during pregnancy on the early differentiation of fetal rat ovaries and testes. J. Devel. Physiol. 13:59-65; 1990.

Rall, T. W. Central nervous system stimulants: The methyxanthines In: Gilman, A. G.; Goodman, L. S.; Rall, T. W.; Murad, F., eds Goodman and Gilman's The pharmacological basis of therapeutics. New York: MacMillan; 1985.

Ramin, S. M.; Kedzierski, W.; Porter, J. C. Action of lead on catcholamine secretory processes of fetal hypothalamic and adrenal cells. Mol. Cell. Neurosci. 4:449-454; 1993.

Robb, G. W.; Amann, R. P.; Killian, G. J. Daily sperm production and epididymal sperm reserves of pubertal and adult rats. J. Reprod. Fertil. 54:103-107; 1978.
Roth, A. C.; Smith, M. K. Nitrite-induced iron deficiency in the neonatal rat. Tox. Appl. Pharmacol. 96:43-51; 1988.

Scanlon, J. W. The neuroteratology of cocaine: background, theory, and clinical implications. Reprod. Toxicol. 5:89-98; 1991.

Sharpe, R. M.; Skakkebaek, N. E. Are oestrogens involved in falling sperm counts and disorders of the male reproductive tract? Lancet 341:1392-1394; 1993.

Siddiqi, T. A.: Meyer, R. A.; Woods, T. R., Jr.; Plessinger. M. B. Ultrasound effects on fetal auditory brain stem responses. Obstet. Gynecol. 74:752-756; 1988.

Snedecor, G. W.; Cochran, W. G. Statistical methods ( 7 th ed.). Ames, IA: Iowa State University Press; 1980:282-288

Stoline, M. R. The status of multiple comparisons: simultaneous estimation of all pairwise comparisons in one-way ANOVA designs. Am. Stat. 35:134-141; 1981.

Tarantal, A. F.; Hendrickx, A. G. Evaluation of the bioeffects of prenatal ultrasound exposure in the cynomolgus macaque (Macaca fascicularis): I. Neonatal/infant observations. Teratology 39:137-147; 1989a.

Tarantal. A. F.; Hendrickx, A. G. Evaluation of the bioeffects of prenatal ultrasound exposure in the cynomolgus macaque (Macaca fascicularis ): II. Growth and behavior the first year. Teratology 39:149-162; $1989 b$.

Whittingham, D. G; Wood, M. J. Reproductive physiology. In: Foster, H. L.; Small, J. D.; Fox, J. G., eds. The mouse in biomedical research (vol. 3). Normative biology, immunology, and husbandry. Boston: Academic Press; 1983:137-164.

Working, P. K. Male reproductive toxicology: Comparison of the human to animal models. Environ. Health Perspect. 77:37-44; 1988.

Zahalka, E. $\Lambda$.; Seidler, F. J.; Lappi, S. E.; McCook, E. C.; Yanai, J.; Slotkin, T. A. Deficits in development of central cholinergic pathways caused by fetal nicotine exposure: differential effects on choline acetyltransferase activity and $\left[{ }^{3} \mathrm{H}\right]$ hemicholinium-3 binding. Neurotox. Teratol. 4:375-382; 1992 